\title{
The performance of China's biomedical innovation: a scientometric analysis
}

\author{
Xiaoli Tang \& Jian Du \\ Institute of Medical Information \& Library, Chinese Academy of Medical Sciences, Beijing 100005
}

Received May 26, 2016; accepted June 7, 2016; published online July 19, 2016

Citation: Tang, X., and Du, J. (2016). The performance of China's biomedical innovation: a scientometric analysis. Sci China Life Sci 59, 1074-1082. doi: 10.1007/s11427-016-5078-6

Recognizing the importance of innovation in science and technology (S\&T) as a driver of continued economic growth, China has introduced new policies to facilitate and encourage innovation and made significant progress in S\&T innovation in the past decade. The total volume of innovation resources is steadily growing. Commensurate with its status as the second largest economy in the world, China ranks second globally now in research and development (R\&D) investment. The R\&D intensity, i.e. R\&D expenditure as a percentage of gross domestic product (GDP), which now stands at $2.1 \%$, is already close to that of an innovative country $(3 \%-4 \%)$. Meanwhile, China ranks first for science and technology workforce in the world in 2014. Resulting from the economic investment and adequacy of S\&T workforce, China has also made great strides in scientific output. Since 2010, China's total number of scientific publications has ranked second in the world for six consecutive years, second only to the US. Moreover, China's status as the second largest country contributor to the Nature Index, demonstrated its strength in high-quality primary research. The number of domestic resident invention patent applications rose to 1 million in 2015, indicating that China continues to top patent application list globally for the fifth consecutive year.

With regard to the citation impact of scientific publications, China now ranks fourth in terms of both total citations and the top $1 \%$ most cited papers as a whole (http://www.nsfc.gov.cn/publish/portal0/tab38/info51767.ht

email: tang.xiaoli@imicams.ac.cn $\mathrm{m})$. However, the average academic impact of Chinese research does not match its exceptional growth in scientific investment and output. While China is making great progress in high-quality publications, it lags behind the world average in many subject areas in terms of Normalized Citation Impact, which takes into account the differences in citations for research fields and time periods and compares the performance of an institution/country to the average performance of the world. Comparing the impact of Chinese academic performance in selected subject areas reveals that China does not have a strength in biological and medical sciences as it does in chemistry and physical sciences. The distribution of publication output by discipline provides an indication of the priority and emphasis of scientific research in different subject areas. According to Science and Engineering Indicator 2016 (http://www.nsf.gov/statistics/2016/ nsb20161/\#/downloads/report), the publication portfolios of the five major producers-US, EU, China, Japan, and India-have distinct differences by academic area. Almost half $(48.7 \%)$ of the US' publications are focused on biological sciences, medical sciences, and other life sciences, compared to $38.2 \%$ for the world at large. But this percentage is only $20.9 \%$ for China, smaller than EU (40.8\%), Japan $(39.6 \%)$ and even India $(36.2 \%)$. China has the highest concentration of publications in engineering $(37.7 \%)$, biological sciences $(12.1 \%)$ and chemistry $(10.6 \%)$, with the medical sciences only accounting for $8.7 \%$, much lower than the world's level (21.2\%). So, while Youyou Tu was awarded China's first Nobel Prize in medical science in 2015 for the work that led to a treatment for malaria that has 
saved countless lives, China lags behind in producing breakthrough research in biomedical sciences with a wide-ranging impact.

There are some research focused on the relationships between R\&D input and scientific output. Nevertheless little of such research, especially empirical research, has been carried out at the country level. When countries in the world are gearing up efforts to increase R\&D investment, it is imperative for policy makers to understand the relationship between $R \& D$ input and scientific output and find efficient ways to better fund scientific research. To this end, using bibliographic data, this paper examines China's biomedical innovation achievements over the past decade from the perspective of R\&D input (the funding for biomedical sciences and S\&T workforce) and scientific output ((publications, especially high-quality publications) and patents (especially high-valued patents) in biomedical sciences). We place China in an international context to understand the key driving forces which affect innovation and suggest remedies to promote China's biomedical innovation.

The publication and citation data was retrieved from Thomson Reuters Web of Science and Incites. The high-quality publications were limited only to top life sciences journals and top clinical research journals. The 33 top life sciences journals, including Science, Nature, Cell, etc., are identified through Nature Index (http://www. natureindex.com/faq\#methodology6). The top 5 and top 18 clinical research journals, including The New England Journal of Medicine, The Lancet, JAMA, Annals of Internal Medicine, and Nature Medicine, etc., are proposed in 2015 by a Lancet article, in which the authors compared the public input and output for biomedical research in the European Union and the United States (Bouillon et al., 2015). The high-value patents are referred to triadic patent families, and key patents of US Food and Drug Administration (FDA) approved drugs, which are analyzed based on the primary data from OECD Statistic, FDA annual Orange Book and United States Patent and Trademark Office (USPTO).

\section{BIOMEDICAL RESEARCH FUNDING AND WORKFORCE}

China's biomedical research took off in recent ten years. From 2004 to 2011, medical research funding increased from 1.6 billion to 4.9 billion dollars, at an annual rate of $16.9 \%$, with the highest annual growth rate in selected countries/regions, including Australia (9.3\%), Japan (6.8\%), Canada (4.5\%), Europe (4.1\%) and the United States $(1 \%)$ (Moses et al., 2015). Despite increasing investments in medical research by the Chinese government, China contributes only $1.8 \%$ of global funding for medical research, much less than United States (44.2\%), Europe (33.4\%), and Japan (14.3\%).

The National Natural Science Foundation of China (NSFC), one of the major funding agencies that support academic research, established the Department of Health Science in 2009. NSFC awarded 1.1 billion RMB (US $\$ 0.18$ billion) in medical research in 2009 and increased its funding to 4.4 billion RMB (US \$ 0.71 billion) in 2013 . Individual institutions such as universities and hospitals alike followed suit and established their own funds. During the period 2000-2013, the number of NSFC funded projects in medical sciences is much less lower than that of other departments. However, in the recent years the field of oncology lists at the top of all 86 research areas in terms of both the number of projects and funds. Oncology is paid more and more attention because cancer is one of the most deadly diseases, and the risk of cancer is increasing as well (Wu, 2015).

During the period 1996-2011, the US S\&T workforce increased by $2.7 \%$ annually to reach 1.25 million workers. Over the same period, China's workforce increased $6 \%$ annually to reach 1.31 million workers, making it the largest national S\&T workforce in the world. Reliable information about the proportion of medical researchers could not, however, be obtained. But with regard to the talented scientists, according to our investigation, the life sciences and medical sciences account for $25 \%$ of all the "Thousand Talents Program" between 2008 and 2015. There are 485 "Changjiang Scholars" in medical sciences between 1999 and 2015 , accounting for $15 \%$ annually, and 151 scientists were awarded the National Science Fund for Distinguished Young Scholars in medical sciences, accounting for $13 \%$ annually. The two percentages are steadily increasing.

Although China led the world in the overall size of S\&T workforce, it had only 1.9 S\&T workers per 100,000 full-time equivalent employment population, the lowest among the countries for comparison, including United States (8.1), United Kingdom, Germany, Canada, France, Japan, South Korea, Russia and Spain. The investment in capital terms and in labor terms differ widely across countries and regions. The US contributes $44.2 \%$ of global medical research funding but comprises only $21.2 \%$ of the global S\&T workforce. Conversely, China contributes only $1.8 \%$ of global funding for medical research but comprises $22.3 \%$ of the global S\&T workforce.

\section{PUBLICATIONS AND CITATIONS: INTERNATIONAL COMPARISON}

China's capability in biomedical knowledge creation is growing rapidly. Figure 1 shows that during 2006-2010, the number of China's biomedical papers (only article and review included) in the Science Citation Index (SCI) ranked eighth in the world following US, UK, Germany, Japan, Italy, Canada, and France. But during 2011-2015, China ranked second in the world in the number of international biomedical publications. Moreover, China's status as the fourth largest country contributor, which ranked behind US, 
UK and Germany, to the Nature Index demonstrates its strength and progress in high-quality life sciences research.

China quadrupled the global share from $2.4 \%$ (2006) to $10.8 \%$ (2015) for biomedical articles. Over the same period, the global share consistently declined for US, UK, Germany, and Japan, and remained steady for Canada, Italy, and France.

While the total number of biomedical papers for China ranked second behind the US between 2011 and 2015, the volume is only less than $1 / 3$ of that of the US. The Category Normalized Citation Impact (CNCI) divides each publication's citation count by the average citation count of all publications in that subfield and document type in that same year, and thus can be used for comparison. Table 1 illustrates that the average impact of China's medical research publications lagged behind the world average level, and was also below the western nations. Among all publications, only a small share receives more than a handful of citations. Publications that are in the top $1 \%$ of total global citations can be considered to have the highest impact, once properly adjusted for subfield and year. Similar to the CNCI, country and region citation rates for highly cited publications need to be normalized for the share of total publications produced. Citations are calculated by percentile rankings, showing what share of publications are in the top $1 \%$ of the most highly cited literature. A country with a $2 \%$ share of the top $1 \%$ has twice as many highly cited articles as would otherwise be expected, based on its number of publications. During 2006-2015, the US medical publications have a 2.01 and 1.92 share of the top $1 \%$, meaning that these publications were almost twice as likely to be among the top $1 \%$ as would be expected. Such pattern of citations also exists in UK, Germany, Canada, Italy, and France. Although China and Japan have roughly the same average citation impact, the share of publications that are in the top $1 \%$ of the world's citations, and the share of publications collaborated with industry relative to all the country's publications in that period for China were less than Japan and other western countries.

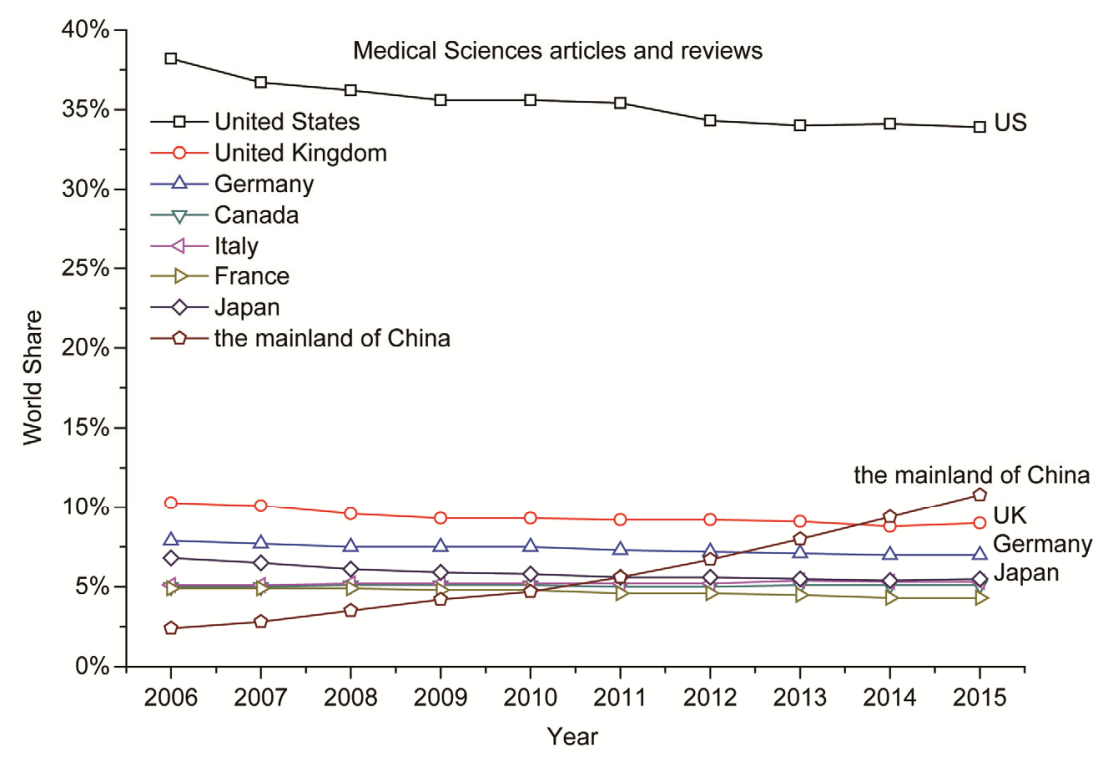

Figure 1 (Color online) The number of China's biomedical papers: international comparison during 2006-2015.

Table 1 The citations of China's biomedical papers: international comparison during 2006-2015

\begin{tabular}{|c|c|c|c|c|c|c|c|c|}
\hline \multirow{2}{*}{ Country } & \multicolumn{2}{|c|}{ Web of Science Documents } & \multicolumn{2}{|c|}{ Category Normalized Citation Impact } & \multicolumn{2}{|c|}{$\%$ Documents in Top $1 \%$} & \multicolumn{2}{|c|}{$\%$ Industry Collaborations } \\
\hline & $2006-2010$ & $2011-2015$ & $2006-2010$ & 2011-2015 & 2006-2010 & 2011-2015 & $2006-2010$ & 2011-2015 \\
\hline US & 667,958 & 768,079 & 1.38 & 1.38 & 2.01 & 1.92 & 3.08 & 2.80 \\
\hline UK & 168,820 & 196,632 & 1.37 & 1.54 & 2.03 & 2.44 & 4 & 4 \\
\hline Germany & 145,780 & 165,261 & 1.22 & 1.42 & 1.73 & 2.12 & 4.07 & 4.69 \\
\hline Canada & 95,010 & 116,904 & 1.41 & 1.5 & 2.09 & 2.24 & 2.92 & 2.72 \\
\hline Italy & 95,761 & 118,798 & 1.26 & 1.4 & 1.72 & 1.93 & 2.46 & 2.54 \\
\hline France & 91,312 & 100,740 & 1.23 & 1.51 & 1.94 & 2.40 & 4.12 & 4.57 \\
\hline Japan & 123,662 & 131,445 & 0.89 & 0.94 & 0.77 & 0.80 & 1.73 & 1.98 \\
\hline $\begin{array}{l}\text { the mainland of } \\
\text { China }\end{array}$ & 75,027 & 202,983 & 0.93 & 0.91 & 0.66 & 0.57 & 0.81 & 0.74 \\
\hline
\end{tabular}




\section{HIGH-QUALITY RESEARCH PUBLICATIONS}

The top 33 life sciences journals and the top 18 clinical research journals are defined by Nature Index and Bouillon et al. (2015), respectively. The journals included in the Nature Index are selected by a panel of active scientists, independently of Nature Publishing Group. The selection process reflects researchers' perceptions of journal quality, rather than using quantitative measures such as Impact Factor. Within the 33 high-quality life science journals included, for multi-disciplinary journals, such as Science, Nature, Proceedings of the National Academy of Sciences of the United States of America (PNAS), and Nature Communications, only articles classified in life science areas are included, i.e. the institution name has such terms as "med", "hlth", "hosp", "life" and "bio" etc.

The first and corresponding author(s) are the most important authors of a paper. We argued that on one hand, the first author is credited with having done most of the research work, and on the other hand, the corresponding author may also has been considered to be primarily responsible for the writing of the paper, though not always (Du and Tang, 2013). In Table 2, the publications in which China's authors act as the first author and/or the corresponding author increased significantly from the period 2006-2010 to the period 2011-2015.

The majority of China's life sciences publications belong to biological chemistry and molecular biology. Today, discoveries and innovations in biological sciences and bio-
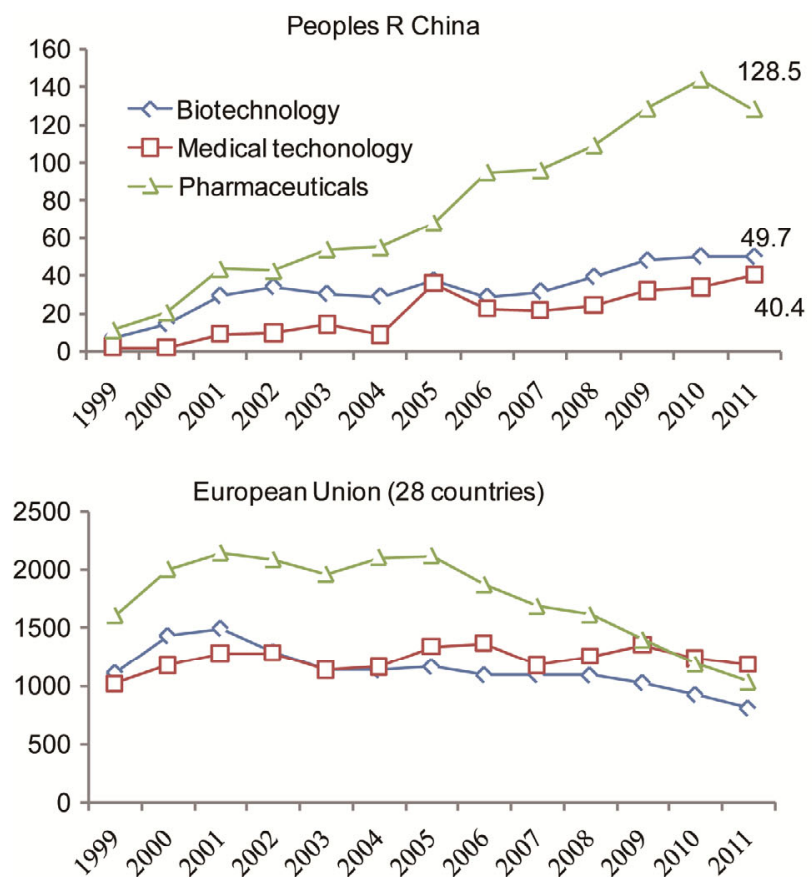

technology continue to revolutionize medical research, resulting in some advances that could not have been imagined even a decade ago. Progress in molecular biology, genomic sciences, cellular and tissue engineering, regenerative medicine, proteomic technologies, bioengineering, bio-imaging, and computational methods are among the many advances that have served to accelerate the tempo of biomedical research, to create unprecedented opportunities for advancing medical science, and to hold promise for improving clinical care and health outcomes. These sciences are the basis for the revolutions in personalized medicine (Fontanarosa and Bauchner, 2015). The majority of China's clinical research publications relate to cancer, endocrinology \& metabolism, blood, diabetes, gastroenterology, circulation, and leukemia.

\section{TRIADIC PATENT FAMILIES}

Using counts from a national patent office as an indicator of inventive activity may not differentiate between inventions of minor and substantial economic potential. Triadic patent families are a set of patents filed at three of these major patent offices: the European Patent Office (EPO), the Japan Patent Office (JPO) and the United States Patent and Trademark Office (USPTO) (OECD, 2016). These triadic patents serve as an indicator of higher-value inventions, and the number of triadic patents is strongly correlated with industrial $R \& D$ expenditures. Triadic patent family counts are fractionally attributed to the countries of residence of the inventor and to the date when the patent was first registered.
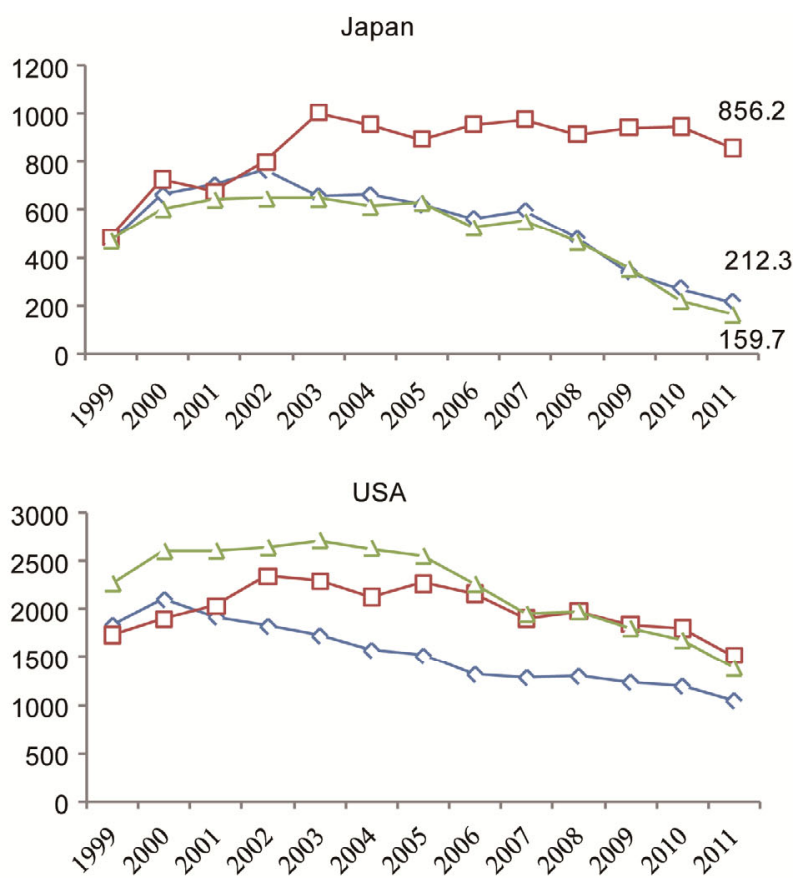

Figure 2 (Color online) US, EU, Japan and China's triadic patent families in the fields of biotechnology, medical technology and pharmaceuticals. Source: OECD Statistic 2016 http://stats.oecd.org/Index.aspx?DatasetCode=PATS_IPC. 
According to OECD.Stat (http://stats.oecd.org/Index. aspx? DatasetCode=PATS_IPC) updated on 12 May 2016, the total number of China's triadic patent families in the fields of biotechnology, medical technology and pharmaceuticals is ranked below the developed countries, with only a global share of $0.8 \%, 0.4 \%$, and $1.5 \%$, respectively (Table 3). Over the same period, the US' global share in these three fields are more than $40 \%$, whereas Japan's global share are $15 \%, 18 \%$, and $10 \%$ in these three fields, respectively.

It should be noted that the number of China's pharmaceutical triadic patent families is rapidly increasing from 1999 to 2011, compared with the steadily declining trend of the US, EU and the sharply declining trend of Japan (Figure 2).

\section{CHINA'S PATENTS GRANTED BY THE UNITED STATES AND EUROPEAN UNION}

The USPTO and EPO patent database were used with the purpose of facilitating comparison and removing any internal bias in the grants made by inventors. The patents analyzed in this research come from IPC class $\mathrm{A} 61 \mathrm{~K}$ and/or A61P for the period 1976-2015. Class A61K corresponds to "preparations for medical, dental, or toilet purposes", while class A61P belongs to "specific therapeutic activity of chemical compounds or medicinal preparations". In the above two classes, there are totally 2,006 and 832 patents granted by the USPTO and the EPO, respectively to Chinese inventors and/or assignees during the period 1988-2015. China's biomedical patents granted by the US and the EU are also increasing (Figure 3).

China's first medical patent granted by USPTO appeared in 1988, about "pharmacologically active bicyclic lactams" (US4757064), with Bayer Aktiengesellschaft (DE) and Chinese Academy of Medical Sciences (CN) as the assignees. China's first independently invented patent was granted by USPTO in 1989, about "topical application of glyciphosphoramide", with Chinese Academy of Medical Sciences $(\mathrm{CN})$ as the assignee. Since the Project "Creation \& Development of Innovative Drugs" initiated in 2008, the count of patents sharply increased. The Chinese government launched the project "Key Drug Innovation" in 2007, which provides $R \& D$ funding for the pharmaceutical sector. The project provided \$ 1 billion during 2011-2015 and is expected to add investments to approximately $\$ 4.3$ billion by 2020 (Ding et al., 2011). As an important national project, Key Drug Innovation aims to develop a series of innovative drugs for treating ten major diseases. Since the project's inception, China's drug innovation has been greatly impelled.

The most popular technology area for both USPTO and EPO patents granted to Chinese inventors/assignees is "medicinal preparations containing organic active ingredients" (A61K-031/00). Nevertheless, the technology area patterns of China's patents differ between USPTO and
Table 2 Top Journals' publications in which China's authors act as the first authors and/or the corresponding authors ${ }^{\text {a) }}$

\begin{tabular}{|c|c|c|}
\hline Top Life Sciences Journals & $\begin{array}{c}2006- \\
2010\end{array}$ & $\begin{array}{r}2011- \\
2015 \\
\end{array}$ \\
\hline Journal of Biological Chemistry & 461 & 1,029 \\
\hline $\begin{array}{l}\text { Proceedings of the National Academy of Sciences of the } \\
\text { United States of America }\end{array}$ & 149 & 414 \\
\hline Nature Communications & 1 & 335 \\
\hline Journal of Neuroscience & 75 & 193 \\
\hline Nature & 26 & 90 \\
\hline Nature Genetics & 24 & 94 \\
\hline Science & 29 & 61 \\
\hline Molecular Cell & 18 & 50 \\
\hline Proceedings of the Royal Society B-Biological Sciences & 29 & 39 \\
\hline Journal of Clinical Investigation & 17 & 45 \\
\hline Cell & 14 & 47 \\
\hline Embo Journal & 25 & 36 \\
\hline American Journal of Human Genetics & 25 & 29 \\
\hline Current Biology & 13 & 38 \\
\hline Cell Stem Cell & 8 & 42 \\
\hline Developmental Cell & 9 & 40 \\
\hline Genome Research & 22 & 26 \\
\hline Genes \& Development & 11 & 36 \\
\hline Ecology & 11 & 31 \\
\hline Journal of Cell Biology & 13 & 29 \\
\hline Nature Cell Biology & 15 & 27 \\
\hline Neuron & 14 & 24 \\
\hline Nature Immunology & 14 & 22 \\
\hline Nature Neuroscience & 14 & 18 \\
\hline Nature Structural \& Molecular Biology & 2 & 29 \\
\hline Nature Medicine & 7 & 23 \\
\hline Plos Biology & 1 & 28 \\
\hline Cell Metabolism & 8 & 20 \\
\hline Nature Biotechnology & 6 & 21 \\
\hline Immunity & 5 & 19 \\
\hline Ecology Letters & 4 & 18 \\
\hline Nature Chemical Biology & 2 & 14 \\
\hline Nature Methods & 0 & 8 \\
\hline Cancer Research & 146 & 172 \\
\hline $\begin{array}{l}\text { Journal of Clinical Endocrinology \& Metabo } \\
\text { lism }\end{array}$ & 40 & 151 \\
\hline Blood & 72 & 103 \\
\hline Diabetes & 31 & 95 \\
\hline Gastroenterology & 38 & 70 \\
\hline Circulation & 24 & 35 \\
\hline Leukemia & 31 & 24 \\
\hline Lancet & 18 & 35 \\
\hline Journal of the American College of Cardiology & 21 & 31 \\
\hline Clinical Journal of the American Society of Nephrology & 11 & 31 \\
\hline European Heart Journal & 17 & 20 \\
\hline $\begin{array}{l}\text { American Journal of Respiratory and Critical Care } \\
\text { Medicine }\end{array}$ & 13 & 21 \\
\hline Nature Medicine & 7 & 23 \\
\hline New England Journal of Medicine & 14 & 16 \\
\hline Annals of the Rheumatic Diseases & 7 & 19 \\
\hline JAMA-Journal of the American Medical Associ ation & 8 & 8 \\
\hline Annals of Internal Medicine & 8 & 5 \\
\hline Archives of Internal Medicine & 8 & 0 \\
\hline
\end{tabular}

a) Only articles and review are included. Nature Communications was created in 2010 . 
Table 3 Triadic patent families during 1999-2011 in the fields of biotechnology, medical technology and pharmaceuticals ${ }^{\text {a) }}$

\begin{tabular}{|c|c|c|c|c|c|c|}
\hline \multirow{2}{*}{ Inventor's country of residence } & \multicolumn{2}{|c|}{ Biotechnology } & \multicolumn{2}{|c|}{ Medical technology } & \multicolumn{2}{|c|}{ Pharmaceuticals } \\
\hline & Rank & $\%$ & Rank & $\%$ & Rank & $\%$ \\
\hline United States & 1 & 41.1 & 1 & 43.4 & 1 & 42.7 \\
\hline European Union (28 countries) & 2 & 30.7 & 2 & 26.8 & 2 & 33.7 \\
\hline Japan & 3 & 14.9 & 3 & 18.7 & 4 & 9.6 \\
\hline Germany & 4 & 9.0 & 4 & 9.4 & 3 & 9.6 \\
\hline United Kingdom & 5 & 5.4 & 5 & 4.8 & 5 & 7.0 \\
\hline Canada & 7 & 2.4 & 14 & 1.2 & 9 & 2.4 \\
\hline Korea & 8 & 2.2 & 11 & 1.5 & 11 & 1.7 \\
\hline Netherlands & 9 & 2.1 & 8 & 2.2 & 15 & 1.3 \\
\hline Denmark & 10 & 1.9 & 15 & 1.1 & 12 & 1.5 \\
\hline Switzerland & 11 & 1.9 & 7 & 2.6 & 7 & 2.6 \\
\hline Australia & 12 & 1.8 & 12 & 1.5 & 14 & 1.3 \\
\hline Sweden & 13 & 1.6 & 10 & 2.1 & 10 & 1.8 \\
\hline Belgium & 15 & 1.2 & 17 & 0.5 & 18 & 1.2 \\
\hline Israel & 16 & 1.1 & 9 & 2.2 & 17 & 1.2 \\
\hline Austria & 17 & 0.9 & 16 & 0.6 & 20 & 0.7 \\
\hline Spain & 18 & 0.8 & 19 & 0.4 & 16 & 1.2 \\
\hline China (People's Republic of) & 19 & 0.8 & 18 & 0.4 & 13 & 1.5 \\
\hline Finland & 20 & 0.5 & 20 & 0.4 & 22 & 0.3 \\
\hline India & 21 & 0.5 & 24 & 0.2 & 19 & 1.1 \\
\hline Singapore & 22 & 0.4 & 23 & 0.2 & 28 & 0.2 \\
\hline Norway & 23 & 0.4 & 22 & 0.3 & 21 & 0.4 \\
\hline New Zealand & 24 & 0.3 & 25 & 0.2 & 25 & 0.2 \\
\hline Chinese Taipei & 25 & 0.3 & 26 & 0.2 & 23 & 0.3 \\
\hline
\end{tabular}

a) Source: OECD Statistic 2016. http://stats.oecd.org/Index.aspx?DatasetCode=PATS_IPC

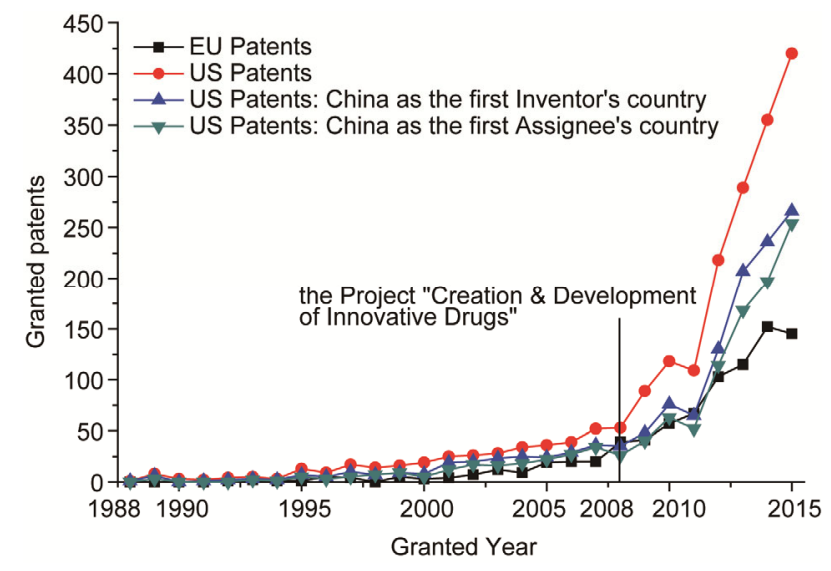

Figure 3 (Color online) Medical patents granted by USPTO and EPO to Chinese in ventors and/or assignees during the period 1988-2015

EPO. China's patents granted by USPTO are relative to basic research, for example, the other top 10 technology areas are "biocides, pest repellants or attractants, or plant growth regulators containing heterocyclic compounds", "heterocyclic compounds containing two or more hetero rings, having nitrogen atoms as the only ring hetero atoms, at least one ring being a six-membered ring with only one nitrogen atom", "medicinal preparations of undetermined

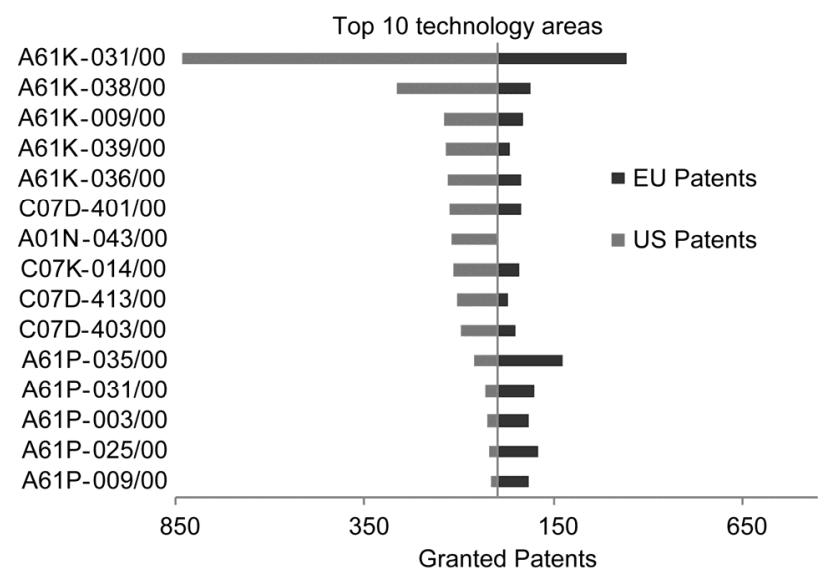

Figure 4 Top 10 technology areas of USPTO and EPO for patents granted to Chinese inventors/assignees

constitution containing material from algae, lichens, fungi or plants, or derivatives thereof, e.g. traditional herbal medicines", "medicinal preparations containing antigens or antibodies", "medicinal preparations characterized by special physical form" and "medicinal preparations containing peptides". While China's patents granted by EPO are relative to drug development, for example, the other top 10 technology areas are "drugs for disorders of the cardiovascular system", 
"drugs for disorders of the nervous system", "drugs for disorders of the metabolism", "antiinfectives, i.e. antibiotics, antiseptics, chemotherapeutics" and "antineoplastic agents".

\section{KEY PATENTS REFERRING TO USFDA APPROVED DRUGS INVENTED BY CHINA}

The United States is the world's largest pharmaceutical market, comprising roughly $40 \%$ of the world's pharmaceutical revenues and, thus, always acts as benchmark in the scientific drug regulatory system. Moreover, since its relatively rigorous regulatory system of drugs and Intellectual Property (IP), the US is always chosen as the first target market by the majority of worldwide pharmaceutical firms, making it a good environment to examine the worldwide distribution of pharmaceutical innovation. An additional benefit to focusing on drugs marketed in the US stems from its relatively simple regulatory structure. Approval decisions in the United States are made by a single body-the Food and Drug Administration (FDA)—which requires drug companies to list the patents that protect their drugs in the FDA Orange Book. This linkage between drugs and patents facilitates assessment of the location of innovation, because the US Patent and Trademark Office (USPTO) requires that a patent lists all the inventors.

Recent work seems to confirm the dominant status of the US in the global pharmaceutical landscape by investigating the geographical distribution of pharmaceutical innovation, as captured by patent applications referring to new drugs. Friedman (2010) explored the geographical location of pharmaceutical innovation during the time period 20002009 at the country level, separately examining the frequency of drug patent inventors of specific countries (Friedman, 2010). Hu et al. (2013) took the key patents covering all new drugs approved by the Food and Drug Administration between 1996 and 2010 as sample to investigate the role of the US in global pharmaceutical innovation.
In this article, we follow Friedman and $\mathrm{Hu}$ et al. in using US patents to track the global distribution of $R \& D$ in the pharmaceutical sector. Our sample is composed of key patents covering all new drugs approved by the Food and Drug Administration (FDA) from prior to January 1, 1982 to 2015. Key patents of a new drug are identified as relevant patents listed in the annual Orange Book in the same year to approve this drug, in order to avoid noise from insignificant and supplemental technology improvement at the late stage of pharmaceutical lifecycle. In this sense, the innovation in this study is exactly confined to be innovation outputs which are measured by patents related to marketed drugs, rather than innovation inputs or common innovation outputs, e.g. "sleeping" patents without contributions to real-world pharmaceutical products.

Totally, our dataset comprises 3,299 patents of drugs (RX and OTC included, DISCN excluded). The first inventors' country code of FDA approved drug patents are retrieved from the database of the United States Patent and Trademark Office (USPTO). Figure 5 shows the United States has the largest proportion $(61.7 \%)$ of drug patent inventors around the world. The European Union countries accounts for $28.7 \%$ and Japan $5 \%$. The performance of Israel is better than the mainland of China, which only has six patents referring to substances, products and method-of-use of marketed drugs.

In the above six patents, there are four patents in which China also is the assignee, while the other two patents with China as the inventor's country, but not the assignee's country (the assignee is Ferring International). There are only three Chinese invented patents referring to substances, products and method-of-use of two FDA marketed drugs.

\section{Veregen (sinecatechins)}

In 2006, FDA approved the first botanical drug product for Veregen (sinecatechins), for treatment of external genital and perianal warts, showing that new therapies derived from

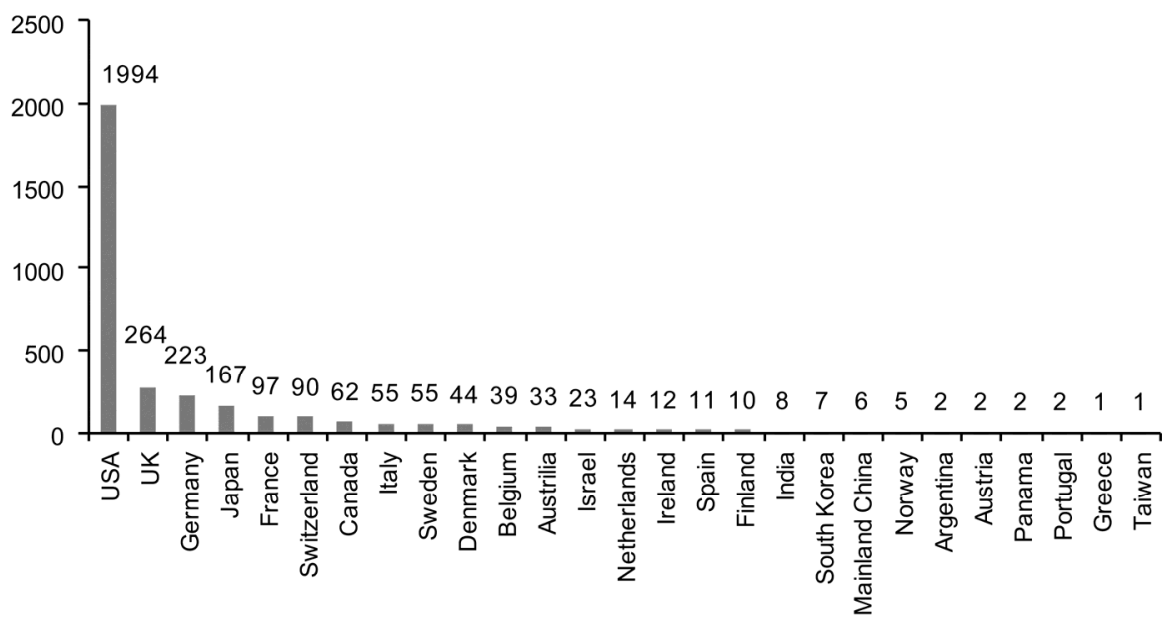

Figure 5 Country or region of the first inventors of key patents referring to FDA approved drugs. 
natural complex mixtures can be developed to meet modern FDA standards of quality, safety, and efficacy. Sinecatechins is a water extract of green tea leaves from Camellia sinensis. It is a mixture of catechins and other green tea components. The key original patents of Veregen are invented by Shujun Cheng, who worked at Cancer Institute (Hospital) of Chinese Academy of Medical Sciences and discovered the inhibition of antioxidant catechins isolated from Chinese green tea on mutagenicity and carcinogenicity in the 1980s. Since 1990, Mitsui Norin Company, Ltd., Tokyo, joined the clinical research. The patent "composition for treating Condyloma acuminata" and "method for treating hyperplasia" were granted by the USPTO in 1998 and 1999. The patents were licensed to Medigene company, Germany for Phase 2 and Phase 3 clinical trials. The Veregen drug was finally approved by FDA on October, 31, 2006.

\section{Coartem (Artemether/Lumefantrine)}

This is a combination of the two medications artemether and lumefantrine. Artemether is one derivative of artemisinin (originally known as qinghaosu), discovered by Youyou Tu and her research group in 1972. In 1981 Qiqing Zhou at the Institute of Microbiology and Epidemiology of the Academy of Military Medical Sciences start to specifically work on artemether. Zhou showed that artemether combined with another antimalarial lumefantrine was the most potent of all antimalarial drugs. He worked alone for four years, and was joined by Dianxi Ning and his team in 1985. They found that in clinical trials the combined tablet (artemether/lumefantrine) had a very high cure rate of severe malaria, more than $95 \%$, including in areas where multi-drug resistance is experienced. They applied for a US patent in 1997. Novartis then noticed the new drug and made a deal for mass production. In 1999 Novartis obtained the international licensing rights and gave the brand name Coartem. It was approved by the USFDA in 2009. It became the first artemisinin-based combination therapy. For this invention he and his team were awarded the European Inventor Award of 2009.

\section{CONCLUSION}

With a substantial increase in research investment, especially in the field of biomedical sciences, China has risen as a major contributor to the global scientific and technological development. The intensity of R\&D expenditure in pharmaceutical industry has been ranked top three in more than 30 domestic manufacturing industries and the $\mathrm{R} \& \mathrm{D}$ expenditure in pharmaceutical industry reached 39.03 billion RMB in 2014. Our investigation indicates that scientific outputs were closely related with the increasing in scientific funds and large S\&T workforce. Meanwhile, the study also indicates that Chinese scholars need to improve their academic impact and develop high-valued patents. In order to improve the country's capability in innovation research and scientific achievements, the following suggestions are proposed.

\section{Funding more basic science.}

While China spent 2.1 percent of its GDP on R\&D in 2014, in line with other developed countries such as the US and the UK, it spent only a fraction of that on basic research. Given that many important advances in applied research originate with advances in fundamental understanding, boosting basic research funding would be a prescient long-term strategy for fostering innovation.

\section{Addressing Gaps in S\&T Workforce.}

While China has the largest base of $\mathrm{PhD}$ students and the largest S\&T workforce in the world, there are two major gaps in its workforce - a lack of lab technicians and post-doctoral fellows, according to Turning Point: Chinese Science in Transition by Nature Publishing Group in 2015 (http://www.nature.com/ press_releases/turning_point.pdf). This is in contrast with the West, which sees a surplus of postdocs, many of whom come from China. Postdocs and technicians are valuable members of the Chinese research environment. Experienced postdocs can make PI's time more scalable and can also play a key role in mentoring junior students and staff. Competent technicians play an increasingly important role as more research requires equipment and technologies needing significant technical skills to use effectively. Addressing these shortages will be critical for Chinese science to continue competing on a global stage, and will probably require a promotion of the value institutes place on these positions. Greater compensation for contract-based researchers, less emphasis on hiring researchers with overseas experience and reforming strict hiring rules are some clear measures that would help address these shortfalls.

\section{Striking a balance between basic research and clinical research}

The US National Institutes of Health (NIH) defines clinical research as research that directly involves human subjects or human tissues. It can be patient oriented research, epidemiological and behavioral studies, or outcomes research and health services research. NIH allocates around $55 \%$ to basic biomedical research and $45 \%$ to applied research (Moses et al., 2015). Despite increasing investments in medical research by the Chinese government, funding for clinical research was only a quarter of that for basic biomedical research (US $\$ 250$ million vs $\$ 1$ billion in 2013) (Jiang et al., 2015).

China accounts for $20 \%$ of the world's population. The patient volume is enormous. Improved patient care and population health is a huge responsibility and should, therefore, be a high national priority for research. In recognition of its importance, the Ministry of Science and Technology of China (MOST) and National Health and Family Planning Commission established 32 national clinical research centers (CRCs) focusing on 11 major diseases between 2013 and 2016. Although highly commendable, a small number of national CRCs might be insufficient to 
Table 4 Key patents referring to FDA approved drugs invented by China

\begin{tabular}{|c|c|c|c|c|c|}
\hline Patent & Drug Approved Year & $\begin{array}{c}\text { Trade_Name/ } \\
\text { Ingredient }\end{array}$ & Applicant & Inventors & Assignees \\
\hline $\begin{array}{c}\text { Method for treating hyperplasia } \\
\text { Patent Number: US5968973 } \\
\text { Grant year:1999 } \\
\end{array}$ & 2006 & Veregen/Sinecatechins & Medigene AG & \multirow{2}{*}{$\begin{array}{c}\text { ShuJun Cheng }[\mathrm{CN}] \\
\text { Dechang Wang [CN] } \\
\text { Yukihiko Hara }[\mathrm{JP}]\end{array}$} & \multirow{2}{*}{$\begin{array}{c}\text { Cancer Institute (Hospital), Chi- } \\
\text { nese Academy of Medical Scienc- } \\
\text { es, Beijing [CN] } \\
\text { Mitsui Norin Company, Ltd., } \\
\text { Tokyo [JP] }\end{array}$} \\
\hline $\begin{array}{c}\text { Title: Composition for treating } \\
\text { Condyloma acuminata } \\
\text { Patent Number: US5795911 } \\
\text { Grant year:1998 } \\
\end{array}$ & 2006 & Veregen/Sinecatechins & Medigene AG & & \\
\hline $\begin{array}{l}\text { Title: Antimalarial compositions } \\
\text { Patent Number: } 5677331 \\
\text { Grant year: } 1997\end{array}$ & 2009 & $\begin{array}{c}\text { Coartem } \\
\text { /(Artemether+Lumefant } \\
\text { rine })\end{array}$ & Novartis & $\begin{array}{c}\text { Yiqing Zhou [CN] } \\
\text { Dianxi Ning [CN] } \\
\text { Shufen Wang [CN] } \\
\text { Deben Ding [CN] } \\
\text { Guofu Li [CN] } \\
\text { Chengqi Shan [CN] } \\
\text { Guangyu Liu [CN] } \\
\end{array}$ & $\begin{array}{c}\text { Ciba-Geigy AG, Basel }[\mathrm{CH}] \\
\text { Institute of Microbiology and } \\
\text { Epidemiology, Academy of Mili- } \\
\text { tary Medical Sciences, Beijing } \\
{[\mathrm{CN}]}\end{array}$ \\
\hline
\end{tabular}

raise the level of clinical research nationwide. More efforts and investments are warranted at all levels. High-quality clinical studies need substantial investment in expertise, manpower, and infrastructure. We have huge patient resources that can be used to answer many clinical questions. "Setting research priorities which are most likely to deliver improved health outcomes"- the first strategic aim of the UK Medical Research Council-is equally applicable in China (Zhang et al., 2015). With the right policy and sufficient investment at all levels, China has the potential to become a fertile field for clinical research.

\section{Enhancing drug discovery and drug development.}

Drug development is the process of bringing a new pharmaceutical drug to the market once a lead compound has been identified through the process of drug discovery. It includes pre-clinical research on microorganisms and animals, clinical trials on humans, and may include the step of obtaining regulatory approval to market the drug. The nature of a drug development project is characterized by multi-disciplinarity, large capital expenditure, and a long cycle of $R \& D$. As a result, collaboration between pharmaceutical companies and universities or research institutes will help to reduce risk and improve the chances of success. For instance, on March 15, 2016, Huya Bioscience announced that it had signed an exclusive license with China's Fudan University for the ex-China rights to a series of novel immuno-oncology drug candidates discovered by Fudan researchers. At the national level, China has shifted its focus to the establishment of translational medicine centers, which aims at breakthrough of bottlenecks between basic medical research, clinical research and drug development by translating laboratory findings into clinical applications. Five National Centers for Translational Medicine are under construction now, which will greatly promote the development of medical level and drug development in China.

There are several limitations in this study. First, the sample is limited to English journal articles. But in China a substantial number of Chinese authors published papers in Chinese. Excluding Chinese language publications means the results can be biased and cause uncertainty. Second, our investigation is a descriptive study and the results are tentative. Due to the lack of appropriate measurement models and reliable information about the proportion of medical researchers in China, it is hard to precisely estimate the relationship between scientific output and investment in science. For example, our investigation shows that past investments in science are related with current scientific output, but it is uncertain whether R\&D input is related with scientific output per researcher. We will address these limitations in future studies.

Aknowledgement: This study was supported by the National Science and Technology Libarary (NSTL) and the ISTIC and Thomon Reuters Scietometrics Joint Lab.

Compliance and ethics The author(s) declare that they have no conflict of interest.

Bouillon, R., Slordahl, S., Nogueria, M.M., Steinhausen, K., Varela-Nieto, I., Pacini, G., Röllinghoff, M., and Syka, J. (2015). Public investment in biomedical research in Europe. Lancet 386, 1335.

Ding, J., Xue, Y., Liang, H., Shao, R., and Chen, Y. (2011). From imitation to innovation: A study of China's drug $\mathrm{R} \& \mathrm{D}$ and relevant national policies. J Technol Manage Innovat 6, 1-13.

Du, J., and Tang, X. (2013). Perceptions of author order versus contribution among researchers with different professional ranks and the potential of harmonic counts for encouraging ethical co-authorship practices. Scientometrics 96, 277-295.

Fontanarosa, P.B., and Bauchner, H. (2015). Scientific Discovery and the Future of Medicine. JAMA-J Am Med Assoc 313, 145-146.

Friedman, Y. (2010). Location of pharmaceutical innovation: 2000-2009. Nat Rev Drug Discov 9, 835-836.

Jiang, L., Krumholz, H.M., Li, X., Li, J., and Hu, S. (2015). Achieving best outcomes for patients with cardiovascular disease in China by enhancing the quality of medical care and establishing a learning ealth-care system. Lancet 386, 1493-1505.

Moses, H., Matheson, D.H.M., Cairns-Smith, S., George, B.P., Palisch, C., and Dorsey, E.R. (2015). The anatomy of medical research US and international comparisons. JAMA- J Am Med Assoc 313, 174-189.

$\mathrm{Wu}$, J. (2015). Distributions of scientific funding across universities and research disciplines. J Informetr 9, 183-196.

Zhang, J., Huang, H., and Shen, X. (2015). Cultivating and investing in clinical research in China. Lancet 386, 1506-1508.

Open Access This article is distributed under the terms of the Creative Commons Attribution License which permits any use, distribution, and reproduction in any medium, provided the original author(s) and source are credited. 